\title{
10 Supplemental Irrigation for Improved Rainfed Agriculture in WANA Region
}

\author{
T. Oweis* and A. Hachum \\ Integrated Water and Land Management Program, International Center \\ for Agricultural Research in the Dry Areas (ICARDA), Aleppo, Syria; \\ email:*t.oweis@cgiar.org
}

\section{Introduction and Concepts}

Historically, the focus of water resource planning and management has been on blue water resources for irrigation, industry and domestic purposes. Water investments in rainfed agricultural areas, which are usually located at the upstream of river basins, are lacking and mostly focus on stream flows, surface run-off generation and rivers' routing. In water-scarce regions, the green water resource (the soil moisture in the plant root zone) makes up $85-90 \%$ of the precipitation, reflecting the significant portion of the available freshwater that sustains rainfed agriculture. However, green water use and its monitoring and management have received little attention from engineers, planners and policy makers.

About $80 \%$ of the world's agricultural land is rainfed, contributing to at least two-thirds of global food production. In sub-Saharan Africa more than $95 \%$ of farmed land is rainfed. It is almost $90 \%$ in Latin America, 60\% in South Asia, $65 \%$ in East Asia, and $75 \%$ in West Asia and North Africa (WANA) (Rockström et al., 2007). Undoubtedly, irrigation plays a very important role in supplying food. However, the potential for increasing water withdrawals for irrigation is considered quite limited. Despite the higher risks in rainfed agriculture, especially in drought-prone areas, it is widely accepted that the bulk of world food will continue to come from rainfed agriculture.

Irrigation accounts for about $72 \%$ of global and $90 \%$ of developing-country water withdrawals. Water availability for irrigation may have to be reduced in many regions in favour of rapidly increasing non-agricultural water uses in industry and households, as well as for environmental purposes. However, rainfed areas currently account for about $60 \%$ of world food production. Given the importance of rainfed cereal production, insufficient attention has been paid to the potential of production growth in rainfed areas to play a significant role in meeting future food demand. This potential could be realized through adoption of improved management options on a large scale. Farmers' yields in rainfed regions in the developing countries are low largely due to low rainwater use efficiency because of inappropriate soil, water, nutrient and pest management options, lack of seeds of improved cultivars and poor crop establishment. There is a large untapped potential of rainfed agriculture, especially in Asia and Africa, where the bulk of the world's poor live. Lack of clear and sound water policy in rainfed agriculture is among the reasons for the low yield and water productivity in these areas (Rockström et al., 2007, Wani et al., 2008).

There are three primary ways to enhance rainfed agricultural production, namely: (i) to 
increase the effective rainfall use through improved water management; (ii) to increase crop yields in rainfed areas through agricultural research; and (iii) through reformed policies and increased investment in rainfed areas. This chapter focuses on the first way, in which supplemental irrigation (SI) plays a major role in increasing water use efficiency and yields of rainfed crops.

\section{Rainfed environment}

The climate of the rainfed dry areas (arid, semiarid, dry subhumid) is characterized by complex climatic deficiencies, manifested as agricultural water scarcity for rainfed crop production. The rainfall amount, as well as distribution, is not in favour of stable and satisfactory yield. Rainfall is highly unreliable, with strong risks of dry spells during the crop growth season, even during good rainfall years. Interannual and spatial fluctuations of rainfall are high.

Within the dry areas of WANA, because rainfall amounts and distribution are usually suboptimal, moisture-stress periods often occur during one or more stages of crop growth, causing very low crop yields. Variation in rainfall amounts and distribution from one year to another causes substantial fluctuations in production, which can range, in the case of wheat for example, from 0.3 to over $2.0 \mathrm{t} / \mathrm{ha}$. This situation creates instability and negative socio-economic impacts. Even for breeding modern varieties for rainfed areas, the high heterogeneity and erratic rainfall of rainfed environments make plant breeding a difficult task.

\section{Reasons for low rainfall water productivity}

Poverty, drought, low soil fertility and land degradation are the major factors for low rainfall productivity that are challenging the rainfed agriculture in the dry areas (Rockström et al., 2007; Wani et al., 2008). Another reason for low yields in the stressed environments of rainfed areas is soil deficiency in terms of soil infiltration and soil water-holding capacity: all the rainfall does not infiltrate and/or not all that infiltrates is beneficially utilized. Improper cultivars, which are basically bred to withstand drought under irrigated conditions and poor production inputs, such as poor land preparation and lack of fertilizers, are among other reasons for low rainfed production. Widespread deficiency of microand secondary nutrients such as zinc, boron and sulfur, in addition to organic carbon and macronutrient deficiencies, are largely holding back the potential of rainfed areas (Rego et al., 2007; Sahrawat et al., 2007).

Globally, $69 \%$ of all cereal area is rainfed. Worldwide, rainfed cereal yield is about 2.2 $\mathrm{t} / \mathrm{ha}$, which is about $65 \%$ of the irrigated yield (3.5 t/ha). The importance of rainfed cereal production is partly due to the dominance of rainfed agriculture in developed countries. More than $80 \%$ of the cereal area in developed countries is rainfed. The average rainfed cereal yield in developed countries is as high as irrigated cereal yields in developing countries. Irrigation is relatively more important in cereal production in developing countries, with nearly $60 \%$ of future cereal production in developing countries coming from irrigated areas. However, rainfed agriculture remains important in developing countries as well. Rainfed yield in developing countries is around 1.0-1.5 t/ha, which is two- to fourfold less than that of the achievable potential yield on commercial/ researcher-managed plots (Rockström et al., 2007; Wani et al., 2008).

Lack of investment in rural infrastructure and poor water policies are among the reasons for the dramatic gap between potential yields in rainfed areas and the actual yields achieved by farmers. Important policies should include higher priority for rainfed areas in agricultural extension services and access to markets, credit and input supplies. Investment in rainfed areas, policy reform and transfer of technology such as SI and water harvesting requires coordinating efforts among all players, including agricultural researchers, local organizations, farmers, community leaders, nongovernmental organizations (NGOs), national policy makers and donors.

\section{Supplemental irrigation as a response}

Shortage of soil moisture in the dry rainfed areas often occurs during the most sensitive growth stages (flowering and grain filling) of the crops. 
As a result, rainfed crop growth is poor and yield is consequently low. Supplemental irrigation, using a limited amount of water, if applied during the critical crop growth stages, can result in substantial improvement in yield and water productivity. Therefore, SI is an effective response to alleviate the adverse impact of soil moisture stress during dry spells on the yield of rainfed crops. Supplemental irrigation may be defined as the addition of small amounts of water to essentially rainfed crops during times when rainfall fails to provide sufficient moisture for normal plant growth, in order to improve and stabilize yields' (Oweis and Hachum, 2003). By this definition, and since rainfall is the major water supply source for crop growth and production, the amount of water added by SI cannot by itself support economical crop production. In addition to yield increases, SI also stabilizes rainfed crop production (Oweis and Hachum, 2003).

Unlike full irrigation, in which the crop depends mainly on artificial irrigation since the rainfall amount is very limited, the timing and amount of SI cannot be determined in advance, owing to rainfall stochasticity. Supplemental irrigation in rainfed areas is based on the following three basic aspects (Oweis, 1997):

1. Water is applied to a rainfed crop that would normally produce some yield without irrigation.

2. Since rainfall is the principal source of water for rainfed crops, SI is only applied when rainfall fails to provide essential moisture for improved and stable production.

3. The amount and timing of SI are scheduled not to provide moisture-stress-free conditions throughout the growing season but to ensure that a minimum amount of water is available during the critical stages of crop growth, which would permit optimal instead of maximum yield.

Harvest results from farmers' fields showed substantial increases in crop yield in response to the application of relatively small amounts of irrigation water. This increase covers areas with low as well as high annual rainfall. The area of wheat under SI in northern and western Syria (where annual rainfall is greater than $300 \mathrm{~mm}$ ) has increased from 74,000 ha (in 1980) to 418,000 ha (in 2000), an increase of $470 \%$.
Estimated mean annual increase in production cost due to SI (including fixed and variable costs) as compared with rainfed equals US $\$ 150$ per hectare. Estimated mean increase in net profit between rainfed and SI for wheat equals US $\$ 300$ per hectare. The ratio of increase in estimated annual net profit per hectare to estimated difference in annual costs between rainfed and SI is 200\%, which is high (Oweis and Hachum, 2006a).

\section{Source of water for supplemental irrigation}

Probably the first aspect that comes to mind when planning SI for rainfed agriculture in dry areas is the source of water for irrigation. In a developed river basin with full irrigation for the summer crops and rainfed for winter crops (such as in WANA countries characterized by Mediterranean climate), the same water source and irrigation facilities are used for SI. One good example of such a case is the North Jazirah Irrigation Project in Nineva Province, northern Iraq, in which $25 \%$ of the 60,000 ha project area is cultivated under full irrigation in summer and $75 \%$ of the area is under rainfed wheat with SI in winter (Adary et al., 2002). The source of water for the project is the River Tigris.

Groundwater is the most common source of water for SI. In Syria, for example, groundwater represents $60 \%$ of all water used in irrigation. In many dry regions, more than $90 \%$ of the supplemental-irrigated rainfed areas are fed from groundwater. However, the problem of using groundwater for irrigation in the dry areas is the overexploitation of this natural resource. Pumping groundwater in excess of the natural recharge of water to the aquifer endangers sustainability of the development, which depends on this water. Thousands of wells in the region are drying out each year. Groundwater mining in the dry areas is a serious problem that must be carefully considered, taking into account the quantity and quality as well as legal and institutional aspects.

Water harvesting could be very useful in providing the water needed for SI to upgrade the productivity of rainfed crops grown under marginal environments characterized by low and highly variable rainfall. In this case, run-off 
water is collected into a surface or subsurface storage facility for later use as a water supply source for SI. In sub-Saharan Africa and other tropical semi-arid areas, rainwater harvesting, which collects surface run-off, is used to provide most water for SI. Although seasonal rainfall in these environments is higher than around the Mediterranean, its effectiveness is low because of higher evaporation losses and lower soil water-holding capacity at the root zone.

Water often flows in temporary (ephemeral) streams called wadi and could be stored in surface or subsurface reservoirs. Water storage is important when ephemeral flows are not available or run low, at the time when irrigation water is most needed. Surface storage could be small dams, ponds and man-made tanks or small-scale reservoirs in which the source of water is usually ephemeral or intermittent flows in wadis or valleys (Oweis et al., 1999). Several issues, both technical and socio-economic, need to be considered for optimal implementation of this water-harvesting system. There are many scenarios for the management of the waterharvesting reservoir for SI (Oweis and Taimeh, 2001). One scenario is to empty the reservoir as soon as possible after it is filled and water is stored in the soil profile to save water that otherwise would be lost by evaporation and to ensure reservoir space for the next run-off. More water can be stored and utilized but the risk of not having additional run-off after emptying the reservoirs is real. Bridging dry spells through SI of rainfed crops using harvested rainwater can be an interesting option to increase the yield and water productivity (Oweis et al., 1999).

In water-scarce areas, farmers use marginalquality water resources for SI. Whether beneficially used or wasted, marginal-quality water needs appropriate treatment and disposal in an environmentally feasible manner. The protection of public health and the environment are the main concerns associated with such wastewater reuse. The use of saline and/or sodic drainage and brackish groundwater resources is increasing and warrants attention in order to cope with the inevitable increases in salinity and sodicity that will occur. Agricultural drainage water is becoming an appealing option for many countries, not only to protect natural resources from deterioration but also to make a new water resource available for agri- culture. In Egypt, the total reused drainage water is now approximately 7.2 billion $\mathrm{m}^{3} /$ year, some $12 \%$ of total water resources available to Egypt. Treating these drainage waters as a 'resource' rather than as a 'waste' contributes to the alleviation of water scarcity, environment protection and sustainability of agricultural production systems.

\section{Supplemental Irrigation Impact on Rainfed Agriculture}

\section{Productivity increases}

Research results from the International Center for Agricultural Research in the Dry Areas (ICARDA) and other institutions in the dry areas, as well as harvest from farmers, showed substantial increases in rainfed crop yields in response to SI application in low as well as high rainfall regions.

Supplemental irrigation caused rainwater productivity in north-west Syria to increase from $0.84 \mathrm{~kg}$ of grain $/ \mathrm{m}^{3}$ of water (for rainfed) to $1.53 \mathrm{~kg}$ of grain $/ \mathrm{m}^{3}$ of water (at one-third SI), $2.14 \mathrm{~kg}$ grain $/ \mathrm{m}^{3}$ of water (at two-thirds SI) and $1.06 \mathrm{~kg}$ grain $/ \mathrm{m}^{3}$ of water (at full SI). Similarly, for biomass water productivity, the obtained mean values are 2.37, 2.42, 3.9 and $2.49 \mathrm{~kg}$ grain $/ \mathrm{m}^{3}$ of water for rainfed, one-third SI, twothirds SI and full SI, respectively. The results show more significant improvement in SI water productivity at medium SI application rates than at full SI. Highest water productivity was achieved at rates between one-third and twothirds of full SI. Water productivity becomes an issue for farmers only if water is the production factor that most constrains yields or if saving water yields immediate benefits. Guidelines for recommending irrigation schedules under normal water availability conditions need to be revised when applied in water-scarce areas.

In Syria, average wheat yield under rainfed conditions is only $1.25 \mathrm{t} / \mathrm{ha}$, and this is one of the highest in the region. With $\mathrm{SI}$, the average grain yield was up to $3 \mathrm{t} / \mathrm{ha}$. In 1996 , over $40 \%$ of rainfed areas were under SI and over half of the 4 million $\mathrm{t}$ national production was attributed to this practice. Supplemental irrigation not only increases yield but also stabilizes farmers' production (Oweis and Hachum, 2003). 
The average water productivity (i.e. water use efficiency) of rain in producing wheat in the dry areas of WANA ranges from about 0.35 to 1.00 $\mathrm{kg}$ grain $/ \mathrm{m}^{3}$ of water. However, water used in SI can be much more efficient. ICARDA found that $1 \mathrm{~m}^{3}$ of water applied at the right time (when crops suffer from moisture stress) and good management could produce more than $2.5 \mathrm{~kg}$ of grains over the rainfed production. This extremely high water use efficiency is mainly attributed to the effectiveness of a small amount of water in alleviating severe moisture stress during the most sensitive stage of crop growth. This stress usually causes a collapse in the crop development and seed filling and reduces the yields substantially. When SI is applied before such conditions occur, the plant may reach its high potential.

When compared with the productivity of water in fully irrigated areas (rainfall effect is negligible), greater advantage is obtained with SI. In fully irrigated areas with good management, wheat grain yield is about $6 \mathrm{t} / \mathrm{ha}$ using a total amount of $800 \mathrm{~mm}$ of water. This makes water productivity about $0.75 \mathrm{~kg}$ grain $/ \mathrm{m}^{3}$ of water, one-third of that under SI with similar management. Under purely rainfed conditions, the rainwater productivity, however, is only $0.5 \mathrm{~kg}$ grain $/ \mathrm{m}^{3}$ of rainwater (Oweis, 1997). This suggests that water resources are better allocated to SI when other physical and economic conditions are favourable.

\section{Deficit supplemental irrigation}

Deficit irrigation is an optimizing strategy by which crops are deliberately allowed to sustain some degree of water deficit and yield reduction in order to maximize the productivity per unit of water used. One important merit of deficit supplemental irrigation is the greater potential for benefiting from unexpected rainfall during the growing season owing to the availability of larger storage space in the crop root zone. Results on wheat, obtained from farmers' field trials conducted in a Mediterranean climate in northern Syria, reported significant improvement in SI water productivity at lower application rates than at full irrigation as discussed above.

In northern Syria, water-short farmers apply half the amount of full SI water requirements to their wheat fields. By doing so, the area under SI is doubled using the same amount of water, and total farm production increases by $33 \%$. Research in the WANA region has shown that applying only $50 \%$ of full SI requirements causes yield reduction of only $10-15 \%$. A farmer having a 4-ha farm would on average produce $33 \%$ more grains from his farm if he adopted deficit irrigation for the whole area than if the full irrigation were applied to half of the area (Fig. 10.1).

In the highlands of WANA region, frost occurs between December and March, turning field crops dormant. Usually, the first rainfall sufficient to germinate seeds comes late, resulting in a small crop stand when the frost occurs in December. Rainfed yields, as a result, are much lower than anticipated from a good crop stand pre-frost by early sowing in December and applying $50 \mathrm{~mm}$ of SI in October. Application of $50 \mathrm{~mm}$ of SI to wheat sown early has increased grain yield by more than $60 \%$, adding more than $2 \mathrm{t} / \mathrm{ha}$ to the average rainfed yield of 3.2 t/ha (Ilbeyi et al., 2006). Water productivity reached $4.4 \mathrm{~kg}$ grain $/ \mathrm{m}^{3}$ of consumed water compared with water productivity values of wheat of $1-2 \mathrm{~kg}$ grain $/ \mathrm{m}^{3}$ of water under traditional practices.

The mean grain yield for the barley genotypes under Mediterranean climate with total rainfall of $186 \mathrm{~mm}$ was $0.26 \mathrm{t} /$ ha for rainfed, $1.89 \mathrm{t} / \mathrm{ha}$ for $33 \%$ SI, $4.25 \mathrm{t} /$ ha for $66 \%$ SI, and $5.17 \mathrm{t} /$ ha for $100 \%$ SI. The highest yields of one of the genotypes (Rihane-3) were 0.22, 2.7, 4.75 and $6.72 \mathrm{t} /$ ha for the four SI levels, respectively. These dramatic results under SI were obtained partly because of the drought during this season (ICARDA, 1989).

Northern Iraq is a typical rainfed area in WANA (from 300 to $500 \mathrm{~mm}$ seasonal rainfall with non-uniform temporal and spatial distribution). Huge investments in SI systems and infrastructure were made to overcome rainfall shortages. Substantial improvement is made in yield and water productivity in using SI in conjunction with proper production inputs and system management (Adary et al., 2002). In the growing season of 1997/98 (annual rainfall $236 \mathrm{~mm}$ ), rainfed wheat yield in one of the irrigation projects increased from $2.16 \mathrm{t} / \mathrm{ha}$ to $4.61 \mathrm{t} / \mathrm{ha}$ by applying only $68 \mathrm{~mm}$ of irrigation water at the critical time. Application of 


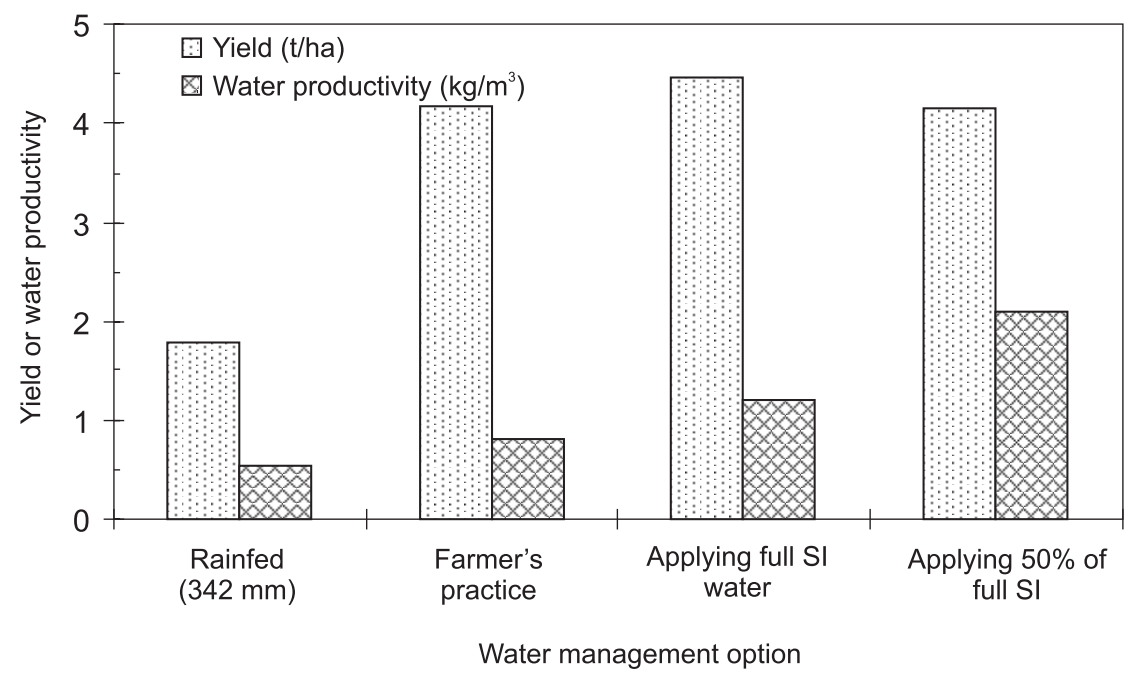

Fig. 10.1. Yield and water productivity for wheat under different water management options for a 4-ha farm in northern Syria (after Oweis and Hachum, 2006b).

100-150 mm of SI in April and May gave maximum results.

In the winter rainfall environment of WANA region, delaying the general sowing date retards crop germination and seedling establishment because of the rapid drop in air temperature starting generally in November. Every week delay after this time results in a $200-250 \mathrm{~kg} / \mathrm{ha}$ yield decrease. With SI, it is possible to decide on the sowing date of the basically rainfed crops without the need to wait for the onset of seasonal rain, with a longer growing season and earlier maturity, which helps the crop to escape terminal drought.

Analysis of 4 years' data (1996-2000) of SI on winter-sown food legumes observed at ICARDA's fields in northern Syria under different water management options has shown significant improvement in yield and water productivity for chickpea, lentil and faba bean (Oweis and
Hachum, 2003). However, lentil and faba bean are more responsive to SI than chickpea (Table 10.1).

\section{Potential of Supplemental Irrigation in WANA}

The governing factor when considering the potential of $\mathrm{SI}$ in rainfed semi-arid areas is the availability of water (blue water) to supplement rainfall in supporting the basically rainfed crop. In many dry areas, there are at least two growing seasons: a dry season (with negligible rainfall) such as summer in the Mediterranean, during which full irrigation is needed, and a wet rainy season such as winter in the Mediterranean, in which the amount and distribution of rainfall are not in favour of desired crop production. All irrigation schemes in such areas are used for full

Table 10.1. Water productivity ( $\mathrm{kg}$ grain/ha/mm) for three legume crops under rainfed and $100 \%$ supplemental irrigation at Tel Hadya, northern Syria.

\begin{tabular}{lccl}
\hline Crop & ${\text { Rainfed }(\mathrm{SI}=0)^{\mathrm{a}}}$ & $100 \% \mathrm{Sl}^{\mathrm{a}}$ & Source of data \\
\hline Chickpea & 4.2 & 4.3 & Oweis et al., 2004a \\
Lentil & 4.0 & 5.1 & Oweis et al., 2004b \\
Faba bean & 5.6 & 6.2 & Oweis et al., 2005
\end{tabular}

a Means of four growing seasons (1996-2000). 
irrigation in summer and SI in winter. In this section, summaries of two case studies, one in Syria and another in Tunisia, for assessing the potential of SI are presented.

\section{The case of Syria}

The irrigation water discharge available (from surface or groundwater) in existing irrigation schemes that are being used to fully irrigate summer crops, within the rainfed proximity, can be used in winter for SI of winter crops. Since water requirements for SI are a fraction of those for full irrigation, the areas that can be irrigated in winter are much larger than areas currently used for full irrigation in summer. The method uses a combination of a simple model to calculate the additional rainfed area that can be partially irrigated by the possible water savings made by the shift from spring/summer fully irrigated crops to supplementally irrigated winter/ spring crops, with a water-allocation procedure for the surrounding rainfed areas based on suitability criteria. In case of water scarcity, some shift (reallocation) may be made from the normally less-efficient full irrigation in summer to highly efficient winter SI.

To assess the impact of adopting SI of winterspring crops over that of using water only for fully irrigated summer crops, two steps are needed. The first is to estimate the water savings that could be achieved, first within each area unit (pixel) of the irrigated area, and then the total savings for the irrigated area or for a specified fraction of the area. The second is to distribute these water savings among pixels that at present are not irrigated but meet specified criteria. The criteria used were based on distance from the irrigated perimeter, slope, soils and presence of forests. The scores obtained against these four criteria were combined in a multi-criteria evaluation using the principle of the most limiting factor.

Distribution rules need to be established that emulate allocation priorities. A simple distribution rule would be one in which those pixels that score best against the different criteria are filled up first, followed by those that score less well, etc. A second distribution rule could be to fill up the pixels in accordance with the allocation priorities established by Rule 1 with a user- specified fraction of the water requirement that is not met by precipitation (Rule 2). Further rules could be put in place but Rules 1 and 2 are sufficiently powerful to simulate fairly complex realities.

By integrating existing information, derived from either thematic maps or satellite imagery, in a GIS (geographical information system), this procedure for calculating water savings and reallocating them for SI is carried out in the case of Syria (De Pauw et al., 2006). In a district with mean long-term annual rainfall of $360 \mathrm{~mm}$, the net crop water requirement for cotton turns out to be $1056 \mathrm{~mm}$, while for wheat it is only $154 \mathrm{~mm}$. This simply means that in this locality, one can potentially grow 7 ha of wheat (under SI) using the same water needed for growing 1 ha of cotton (under full irrigation). However, a lot of technical and economical efforts and inputs need to be considered for its feasibility.

The case study indicated that, in most of the irrigation districts, water saved by shifting from the dry season to the wet season is only partially depleted for SI due to poor soils, topography or distance constraints or SI is basically not needed due to enough rainfall in the area. The ratio of the water depleted to the water saved, called Usable Water Saving Ratio (UWSR), indicates to what extent this condition exists. At the same time it answers the question of what percentage of an irrigation scheme can potentially shift from full irrigation to SI. The UWSR ranged from zero to one.

From this case study, it appears that in Syria a large potential for SI exists by way of shifting from a fully irrigated summer crop to a partially irrigated winter-spring crop. Roughly this potential amounts to more than doubling of the area currently under SI.

\section{The case of Tunisia}

In water-scarce areas, traditional options based on full irrigation with intensive cropping systems are not the relevant choices anymore because of chronic water shortages.

In Tunisia, as in other Maghreb countries, rainfall is almost the only source of fresh water. Mean annual precipitation ranges from $1500 \mathrm{~mm}$ on the peaks of the mountains in the most north-western corner of the country to less 
than $100 \mathrm{~mm}$ in the south. Precipitation variability in time is also very high, both within and between years. Out of a total land area of $155,000 \mathrm{~km}^{2}$, the non-arid area is estimated at $37,000 \mathrm{~km}^{2}(24 \%)$, the arid at $55,000 \mathrm{~km}^{2}$ $(35 \%)$ and desert at $63,000 \mathrm{~km}^{2}(41 \%)$. Hence, the mean total precipitation is $36 \mathrm{~km}^{3}$, out of which only $3 \mathrm{~km}^{3}$ could be potentially collected as run-off water in large dams. Renewable groundwater resources are estimated at $1.8 \mathrm{~km}^{3}$. The ratio of potentially irrigable land to arable land is as low as $9 \%$, reflecting the scarcity of water in the country. Hence, most agricultural systems are based on dry farming with cereals and olive tree cultivation as dominant activities.

In Tunisia, potential areas for developing SI are identified by taking advantage of the available experience in implementing small hill reservoirs to collect water for SI. Existing structures are used as a starting point for a methodological development for mapping the potential site for harnessing run-off water. Concerning soils, a capability index for irrigation was calculated for each soil unit reported in the descriptive soil map of Tunisia. Regional suitability for SI is obtained by an overlay of the two potential maps.

Diverse options are available for SI implementation, which could be applied in largescale irrigation perimeters based on large dams and conveyance systems or in small-scale irrigation from shallow wells or small reservoirs where run-off water is collected. Hill reservoirs or lakes have been recently developed with the objective of collecting surface run-off from the catchment area and storing it in small surface reservoirs in order to give access to water for farmers in remote areas. With watersheds of few hundred hectares, excess rainwater not allocated during the rainy season is diverted to storage in ponds and apportioned for irrigation purposes. The average reservoir capacity varies, typically between 10,000 and 200,000 $\mathrm{m}^{3}$, and the run-off catchment area ranges from 40 to 700 ha (Ben Mechlia et al., 2006).

Unlike large reservoirs, hill lakes are not permanent sources of water and their management is very site specific. Farmers ensure that they have all the water needed and decide on the area that should be put under SI during winter. By the end of the winter season, i.e. in March, the state of the reservoir is of particular interest if late spring or summer irrigation is planned for vegetable crops. A survey conducted during a wet year showed that total water used was on average equivalent to $80 \%$ of the capacity of reservoirs.

Suitability of lands for agriculture land capability is related to their potential for making water and nutrients available to plants and it is based on using existing soil information and a Digital Elevation Model (DEM) for mapping land suitability for surface irrigation. The success of SI depends on the availability of appropriate infrastructure for implementing irrigation programmes within areas of productive lands.

Rainfall amount, watershed area and mean slope determine the run-off water that can be stored in a hill reservoir. However, the determination of the size of the reservoir and its location depends on technical, socio-economic and environmental factors and constraints. When determining the potential for run-off water collection in hill reservoirs, only physical factors could be taken into account. A methodology to map areas suitable for hill reservoirs is developed and implemented in the assessment of SI potential in Tunisia. It involves four steps: (i) identification of existing hill reservoirs from satellite images and determination of their watershed areas from DEMs; (ii) determination of typical size and slope of identified watersheds; (iii) deriving potential sites for hill reservoir construction in the pilot area; and (iv) validation of the methodology.

Practices such as SI and regulated deficit irrigation have the potential to increase productivity and to reduce environmental risk. Full irrigation with intensive cropping systems is not a viable approach in this environment and is probably no longer sustainable, considering the prevailing constraints including investment costs and land degradation.

\section{Economics of Supplemental Irrigation}

Increase in crop production per unit of land or per unit of water does not necessarily increase farm profit, just because of the nonlinearity of crop yield with production inputs, particularly with water and its interaction with other input factors. Therefore, a water management strategy that maximizes yield or water productivity is not 
necessarily the most desirable one, especially in water-scarce areas. Often such a strategy is not the most economical in terms of net return. Actually, the most desirable strategy is somewhere in between these two. In northern Syria, the increase in wheat grain yield due to SI under different annual rainfall is depicted in Fig. 10.2. The levels of SI water to which the crops could be underirrigated without reducing income below that which would be earned for full SI under limited water resources is the best bet. For sustainable utilization of water resources and higher water productivity, the recommendation to SI practitioners under limited water resource conditions is to adopt the scenario that maximizes the profit. For the case depicted in Fig. 10.1 , this scenario results in a sub-maximum (but economically optimal) grain yield of 4-5 t/ha.

Since rainfall amount cannot be controlled, the optimal amount of SI that results in maximum net benefit to the farmers is determined. Knowing the cost of irrigation water and the expected price for a unit of the product, Fig. 10.3 helps in deciding on the optimal amount of SI to be applied under different rainfall zones and various price ratios. This simplified procedure of Figs 10.2 and 10.3 could be developed for any other locality having different rainfall amounts, input costs and product prices.
Farmers in developing countries seldom have the means to monitor soil water depletion. Schedules based on soil moisture tension in the active root zone are useful, but the farmers are unable to use either due to lack of know-how or unavailability of equipment. Methods based on soil water measurements and on plant-stress indicators present some difficulties, particularly for farmers. Tensiometers and plant indicators provide information on the irrigation date only. The farmer still needs information on how much water to apply. Farmers are always criticized for being wasteful and applying excessive water. Actually, the root cause of this inefficient practice is that the farmer does not know how to measure water flow or quantity, and therefore he is applying more than what is needed in order to be on the safe side.

\section{Maximizing Supplemental Irrigation Benefits}

\section{Improving soil fertility}

Supplemental irrigation alone, although it alleviates moisture stress, cannot ensure highest performance of the rainfed agricultural system. It has to be combined with other good farm

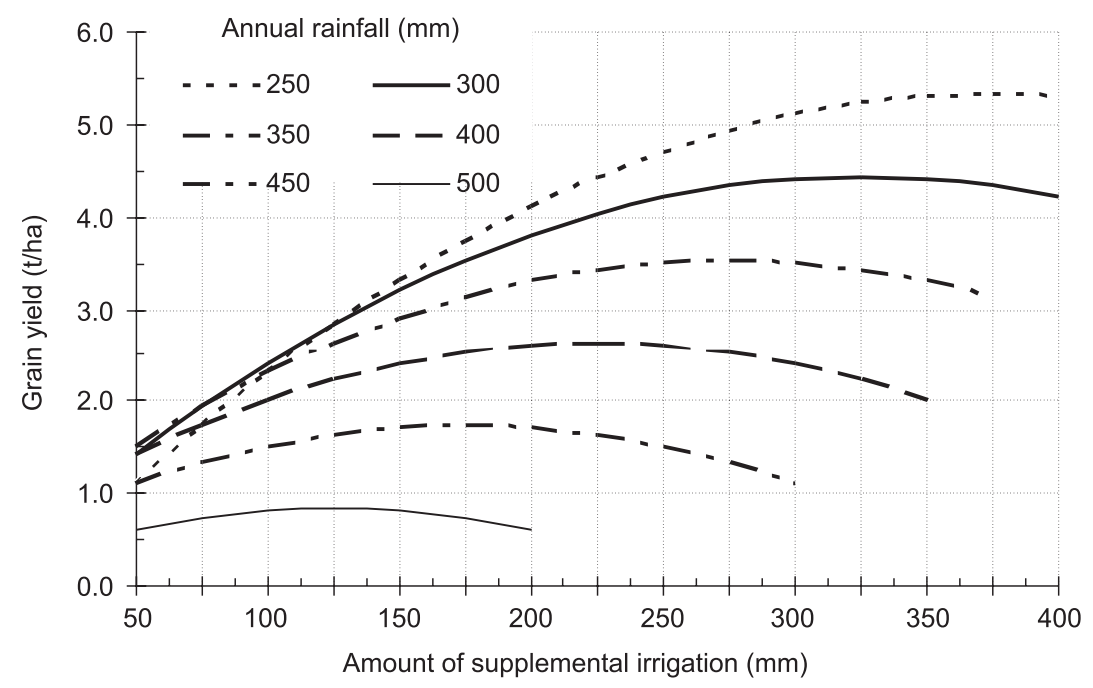

Fig. 10.2. Supplemental irrigation production functions for rainfed wheat in northern Syria under different levels of rainfall (after Oweis and Hachum, 2006b). 


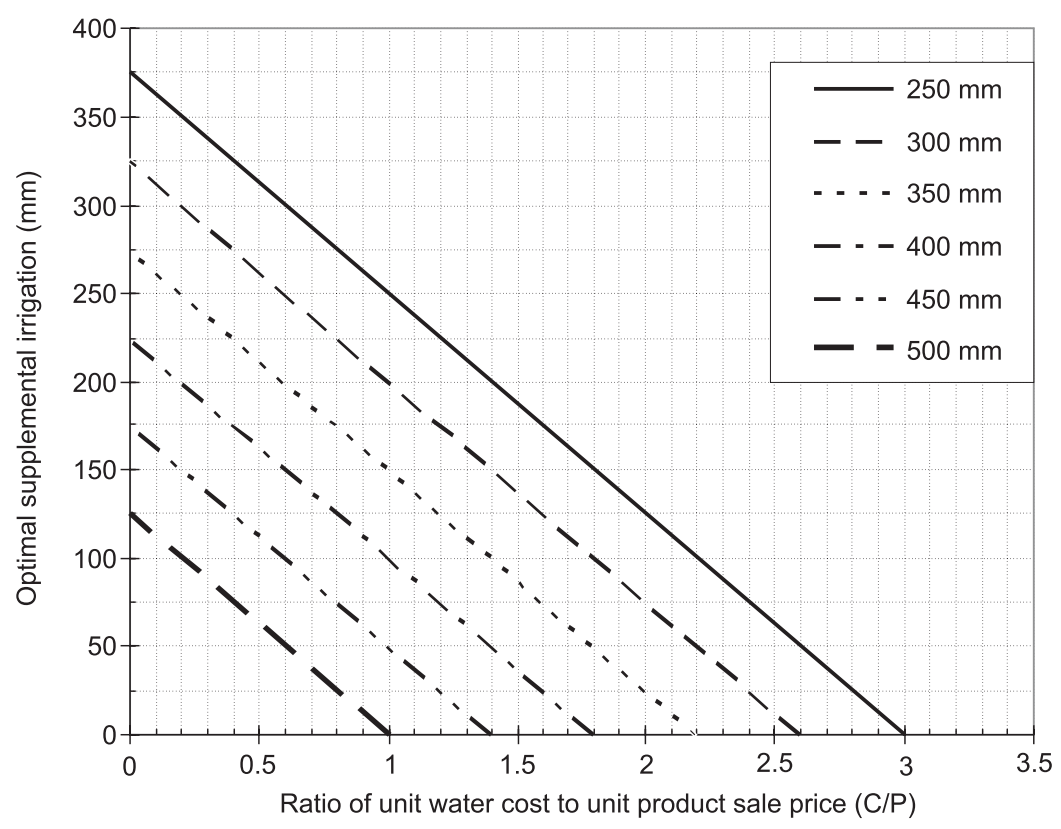

Fig. 10.3. Supplemental irrigation (SI) optimization chart for rainfed wheat in northern Syria under different levels of rainfall (Source: Oweis and Hachum, 2006b).

management practices. Of utmost importance is soil fertility, particularly in the Mediterranean region, where nitrogen deficiency is usually the main issue. Absence of nutrient deficiency greatly improves yield and water use efficiency. Other areas may have different deficiency levels of nitrogen or deficiencies in other elements (Table 10.2). It is always important to eliminate these deficiencies to get potential yield and water productivity. Yield, especially biological, significantly increased with the increase in nitrogen fertilizer, and farmers were strongly advised to

Table 10.2. Gains in water productivity for wheat grain under rainfed and supplemental irrigation with different levels of nitrogen in northern Syria (Source: Oweis and Hachum, 2003).

\begin{tabular}{ccc}
\hline \multirow{2}{*}{$\begin{array}{c}\text { Nitrogen } \\
\text { application rate } \\
(\mathrm{kg} \mathrm{N} / \mathrm{ha})\end{array}$} & \multicolumn{2}{c}{$\begin{array}{c}\text { Water productivity } \\
\left(\mathrm{kg} \text { grain } / \mathrm{m}^{3}\right)\end{array}$} \\
\cline { 2 - 3 } & $\begin{array}{c}\text { Rainfed } \\
\text { water }\end{array}$ & $\begin{array}{c}\text { Irrigation } \\
\text { water }\end{array}$ \\
\hline 0 & 0.54 & 0.81 \\
50 & 0.89 & 1.41 \\
100 & 0.84 & 2.14 \\
150 & 0.81 & 1.40 \\
\hline
\end{tabular}

continuously monitor the nitrogen level in the soil for economical and environmental reasons.

Research in Burkina Faso and Kenya has shown that SI of $60-80 \mathrm{~mm}$ can double, and even triple, grain yields from the traditional $0.5-1 \mathrm{t} / \mathrm{ha}$ (sorghum and maize) to 1.5-2.5 $\mathrm{t} / \mathrm{ha}$. However, most beneficial effects of SI were obtained only in combination with soil fertility management. The major constraint to SI development in Africa is farmers' capacity, both technical and financial, to develop storage systems for run-off water (Rockström et al., 2003).

\section{Appropriate sowing dates}

One of the practical cases of SI is that all the fields may need irrigation at the same time in spring. This case happens when, during the growing season, a rain event with sufficient amount capable of filling the root zone in the entire farm to field capacity occurs. The situation calls for a very high water supply and a large irrigation system. A staggered-sowing strategy reduced the peak farm water demand rate by 
more than $20 \%$, thus potentially allowing a reduction in the irrigation system size and cost (Oweis and Hachum, 2001). Also, the water demand of a larger area can be met with the same water supply.

\section{Improved cultivars}

To get the best out of SI, the proper waterresponsive cultivars need to manifest a strong response to limited water applications, which means that they should have a relatively high yield potential. At the same time, they should maintain some degree of drought resistance, and hence express a good plasticity.

Using both traditional breeding techniques and modern genetic engineering, new crop varieties can be developed that can increase the water use efficiency while maintaining or even increasing the yield levels. For example, through breeding, winter chickpea and drought-resistant barley varieties that use substantially less water have been developed. The chickpea crop is traditionally sown in spring. Consequently, terminal drought stress occurs, causing low yields. This was avoided by early planting with cold-tolerant cultivars developed by ICARDA. On-station as well as on-farm trials have demonstrated that increases in yield and water productivity of $30-70 \%$ are possible by adopting early sowing. Currently, winter chickpea is spreading fast among the farmers in the WANA region.

Data of farm yield under SI in northern Iraq indicate that SI has more impact on bread wheat varieties as compared with durum varieties. Also SI has increased yield of bread wheat varieties by more than $100 \%$, whereas the increase in yield for the durum wheat varieties ranged between 58 and $81 \%$ (ESCWA, 2003).

\section{Efficient supplemental irrigation system}

Implementing precision irrigation such as trickle and sprinkler systems, laser levelling and other techniques contributes to substantial improvement in water application and distribution efficiency. Currently, farmers use three major irrigation methods in practice: surface irrigation methods, including basins, furrows and border strips; sprinkler irrigation methods, including set systems, travelling guns and continuous-move systems; and trickle irrigation methods, with drip, micro-sprinklers and subsurface systems. These systems vary greatly in their application, distribution and storage efficiencies.

The major contribution of irrigation systems to improved SI performance is in making water more available in amount and timing for plant growth. The key factor in successful irrigation is the control of water at all times and levels of water conveyance, distribution and field application. For large field crops, a high degree of water control is inherently built in to most of the sprinkler systems owing the nature of this system. Although drip or micro-irrigation systems offer higher levels of water control than the sprinkler system, they are only recommended for trees and row crops. This brings another important factor into the picture of SI system and improved water management, which is flexibility. Sprinkling is a flexible irrigation system for several reasons. The top five reasons are: (i) there is no need for land grading or reshaping (which is a basic requirement for successful surface irrigation); (ii) the same system can fit different types of soil and crop; (iii) portability allows the use of the system on many farms at different locations during the same season; (iv) the higher degree of control of water allows the application of small irrigations, which is suitable for SI; and (v) dual uses of the system for other purposes such as chemical application and crop cooling (during summer). A portable sprinkler system can be efficiently used for supplemental irrigation to serve a large cropped area during spring, when the rain is insufficient for the crop, by utilizing a small-flow-rate water source such as a well or a water-harvest pond. This is an important factor in which sprinkler irrigation is superior to surface irrigation in water-short regions.

Although surface irrigation is relatively inexpensive and does not require high technical skill, it is recommended for SI when proper land grading is made to the field or small basins are used. Surface irrigation can be made suitable for SI by using the following techniques:

- Surge flow irrigation: by applying water intermittently, instead of continuously, to the furrow, higher distribution uniformity along 
the run is achieved due to reduced infiltration rate upstream.

- Wide bed furrows: partial supply of irrigation water to the cropped land can be useful under deficit irrigation management.

- Alternate water application to furrows: irrigating every other furrow in one irrigation cycle and then irrigating the dry furrows skipped in the previous cycle has shown some savings in water application.

- Level basin: this is a conventional surfaceirrigation method that can achieve very high application efficiency if properly implemented.

\section{Farm water control and measurements}

Controlling and quantifying water application requires flow measurement. If water runs off the field, both inflows and outflows must be measured. Flow measurement of canal water supplies is often inadequate or completely lacking. Run-off is seldom measured. Without flow measurement to quantify applications, it is impossible to evaluate the performance of an irrigation practice. Without such evaluations, it is useless to attempt improving the performance of the irrigation services.

An important issue related to $\mathrm{SI}$ is the timing of water delivery. Within large irrigation schemes, a farmer has little control on the water distribution among the sectors of the scheme and hence the timing of irrigation water delivery to his farm. This may not match the timing of irrigation and thus adversely affects irrigation scheduling and consequently crop yield and water use efficiency. The on-demand water-delivery system is best suited to SI. This is what small farms use, drawing water from wells or nearby surface water.

\section{Enabling environments}

Integrated and participatory research and development (PR\&D) programmes offer the best way to bring SI technologies and practices to their full potential. Any development or applied research programme that underestimates the role of farmers is doomed to failure. Acceptance of SI by men and women farmers is a condition for its success. For pilot tests, staff and farmers may select a water basin using agreed criteria. An integrated $R \& D$ programme will be designed and implemented in a way that involves local communities, institutions and decision makers. The following issues must be taken into consideration:

- Farmers should see the benefits of a project as early as possible. Motivating and promoting awareness among farmers with regard to the project objectives and the ways to achieve them are essential. Implementation requires commitment and cooperation of neighbouring farmers (or communities) in the coordination and management of their limited water resources.

- The specific needs of a local community or a group of beneficiaries must be understood and designed into an appropriate system, bearing in mind the major role often played by women in agricultural work. Farmers' acceptance of a new technology depends on their attitudes toward production risk. Riskaverse farmers will accept a new technology if they perceive that increased returns would more than compensate for any increase in risk.

- To prevent inequality at the village level from widening as a result of the introduction of SI, special care should be taken to make sure that poor and women farmers have equal access to the technique.

- Most dry-area ecosystems are fragile and do not adjust easily to change. If the introduction of SI changes suddenly the use of, for instance, natural resources, especially land and water, the environmental consequences can be far greater than anticipated.

- The necessary conditions for adoption of new technologies are often location specific because they are influenced by cultural differences, education and awareness of a need for change. Users of land and water resources are usually aware of land degradation, but they may not be able to do anything about it if survival is their primary concern. They are unlikely to take up a new practice unless they are convinced that it is financially advantageous, does not conflict with other activities they consider important, and does not demand too much of their time for maintenance. 
- Institutional capacity building, water resources management policies, and management and maintenance programmes are keys to success. Multiple plantings to increase rainfall utilization should become standard practice under SI. Therefore, farmers need to be knowledgeable about water-stress-sensitive growth stages and correct timing of water application.

- Policy reform and public awareness are important issues. Policies related to water use and valuation should be geared towards controlling water use, reducing water demand, safe use and disposal of water, and encouraging the collective approach in using and managing water by users. These policies must be balanced, workable and feasible, otherwise they will be difficult to implement and/or enforce. Policy and institutional aspects of using marginal-quality water in agriculture should examine: the present scenarios to overcome policy and institutional constraints; capacity-building options for the national agricultural and extension systems; and the awareness among the farmers for greater understanding of the potentials of plants, soil and water for the agricultural produce from marginal-quality water (Oweis and Hachum, 2006a).

\section{Demand management and water pricing}

Farmers generally tend to over-irrigate. Most SI developments depend on groundwater as a source for irrigation water. Mining groundwater is now a common practice in the region, risking both water reserves and quality. Water demand management in agriculture is the management of water through influencing consumer behaviour by introducing incentives to use water more efficiently. This will involve many elements, such as legislative measures, including a pricing mechanism and financial incentives as well as penalties. It also involves direct technical measures to control and ration water by flowregulating devices. However, effective public awareness programmes should come at the top of the action list to arrive at fruitful management for water demand. It requires that all users recognize and accept that water supplied to them has a value that varies depending on the purpose of its use. Farmers should understand that the opportunity cost of this water is very high and what they are paying is a small fraction of its real value. Media and extension services can play a role in generating this awareness.

Water pricing is difficult to implement in most of the developing countries. The major reasons for it are not only economic but also cultural and socio-political. Water is seen as a gift of God to humankind and it should be accessible to all. If a pricing mechanism is to be implemented, care must be taken to consider the limited capacity of the resource-poor farmers in addition to other constraints. Effective alternatives to water pricing as a means of demand management are yet to be developed in these countries.

\section{Investment in Supplemental Irrigation}

Risk weighs on the daily lives of poor rainfed farmers, and investment packages have to help reduce that risk. Risks include not only climatic and limited access to reliable technology and water but also unstable land tenure and poorly functioning product and credit markets. Investing in SI can have a significant impact on justified returns from dry farming systems. Biophysical returns on water with SI are higher than those under conventional irrigation, and are highest with deficit applications, a powerful message in water-scarce localities. An integrated investment package including water-harnessing and irrigation technology, irrigation scheduling, training, and cropping and fertilizing guidance is probably the best. Combined soil and water management investments can also have a high return. The key requirements for successful investment in SI include:

- Determining the most appropriate scheduling, crops and cropping patterns, and socioeconomic feasibility.

- Strong water-user associations with incentives for local communities to use water efficiently.

- Managing the economic and environmental consequences of using water in SI.

- Developing policies that foster an enabling environment for the adoption of waterefficient technologies.

The on-demand water-delivery system is best suited to SI. This is what small farms use, draw- 
ing water from wells or nearby surface water. Supplemental irrigation must be properly integrated with other production inputs, including crop and soil management options, improved germplasm and fertilizers to achieve the desired output. Farmers need to understand the technology and how to use it. Extension and human capacity building should play a major role in this respect. Long-term training and advisory programmes should be designed and implemented. It is recommended that practitioners use incentives for farmers' participation, technology transfer and water-cost recovery to prompt adoption of improved management options. In rainfed dry areas, where water is more limiting than land, it is better to maximize yield per unit of water and not yield per unit of land. Inputs other than water and improved cultural practices are also necessary for maximizing profits.

The investment opportunities in SI may focus on reforming policies and regulations to govern groundwater development and operation; strengthening or creating water-user associations; financing water resources development for SI through the source, the conveyance system, and the field-irrigation systems; developing low-cost, low-energy irrigation systems such as drip or sprinkler, including pumping; strengthening extension services; and developing simple and practical tools for SI scheduling.

\section{Conclusions}

In rainfed dry areas, where water is more limiting than land, it is better to maximize yield per unit of water and not yield per unit of land. Inputs other than water and improved cultural practices are also necessary for maximizing profits. Supplemental irrigation boosts yield and helps stabilize rainfed agriculture. For the greatest benefit, it must be part of an integrated package of farm cultural practices. Supplemental irrigation that is optimized through on-farm water management policies and timely socio-economic interventions is essential for the sustainable use of limited water resources, particularly groundwater. A water management strategy that maximizes yield or water productivity is not necessarily the most desirable one, especially in water-scarce areas. Actually, the most desirable strategy is somewhere in between these two. Policies related to water use and valuation should be geared towards controlling water use, reducing water demand, safe use and disposal of water, and encouraging the collective approach in using and managing water by users. These policies must be balanced, workable and feasible, otherwise they will be difficult to implement and/or enforce. Integrated and participatory research and development (PR\&D) programmes offer the best way to bring SI technologies and practices to their full potential. Investment opportunities in supplemental irrigation may focus on reforming policies and regulations to govern groundwater development and operation, strengthening or creating water-user associations and financing water resources development for SI. Integrated and participatory research and development programmes offer the best way to bring SI technologies and practices to their full potential.

\section{References}

Adary, A., Hachum, A., Oweis, T. and Pala, M. (2002) Wheat productivity under supplemental irrigation in northern Iraq. On-Farm Water Husbandry Research Report Series No. 2. International Center for Agricultural Research in the Dry Areas (ICARDA), Aleppo, Syria.

Ben Mechlia, N., Oweis, T., Masmoudi, M., Anane, M. and Sghaier, N. (2006) Assessment of supplemental irrigation potential in semi arid areas: methodology and a case study from Tunisia. Research Report. International Center for Agricultural Research in the Dry Areas (ICARDA), Aleppo, Syria.

De Pauw, E., Oweis, T., Nseir, B. and Youssef, J. (2006) Spatial modelling of the biophysical potential for supplemental irrigation: methodology and a case study in Syria. Research Report. International Center for Agricultural Research in the Dry Areas (ICARDA), Aleppo, Syria.

ESCWA (Economic and Social Commission for Western Asia) (2003) Enhancing Agricultural Productivity through On-Farm Water Use Efficiency: an Empirical Case Study of Wheat in Iraq. In collaboration with ICARDA and IPA Agricultural Research Center of Iraq. ESCWA, Beirut, Lebanon. 
ICARDA (International Center for Agricultural Research in the Dry Areas) (1989) Farm Resource Management Program Annual Report for 1989. ICARDA, Aleppo, Syria.

Ilbeyi, A., Ustun, H., Oweis, T., Pala, M. and Benli, B. (2006) Wheat water productivity and yield in a cool highland environment: Effect of early sowing with supplemental irrigation. Agricultural Water Management 82, 399-410.

Oweis, T. (1997) Supplemental Irrigation: a Highly Efficient Water-use Practice. ICARDA, Aleppo, Syria.

Oweis, T. and Hachum, A. (2001) Reducing peak supplemental irrigation demand by extending sowing dates. Agricultural Water Management 50, 109-123.

Oweis, T. and Hachum, A. (2003) Improving water productivity in the dry areas of West Asia and North Africa. In: Kijne, W.J., Barker, R. and Molden, D. (eds) Water Productivity in Agriculture: Limits and Opportunities for Improvement. CAB International, Wallingford, UK, pp. 179-197.

Oweis, T. and Hachum, A. (2006a) Water management in rainfed agriculture - investing in supplemental irrigation. In: Agricultural Water Sourcebook: Shaping the Future of Water for Agriculture. The World Bank, Washington, DC, USA, pp. 206-213.

Oweis, T. and Hachum, A. (2006b) Water harvesting and supplemental irrigation for improved water productivity of dry farming systems in West Asia and North Africa. Agricultural Water Management Journal 80, 57-73.

Oweis, T. and Taimeh, A. (2001) Farm water-harvesting reservoirs: issues of planning and management in dry areas. In: Adeel, Z. (ed.) Integrated Land Management in Dry Areas. Proceedings of a Joint UNU-CAS International Workshop, Beijing, China, 8-13 Sept 2001. UNU, Tokyo, Japan, pp. 165-182.

Oweis, T., Hachum, A. and Kijne, J. (1999) Water harvesting and supplemental irrigation for improved water use efficiency in the dry areas. SWIM Paper 7. International Water Management Institute, Colombo, Sri Lanka.

Oweis, T., Hachum, A. and Pala, M. (2004a) Water use efficiency of winter-sown chickpea under supplemental irrigation in a Mediterranean environment. Agricultural Water Management Journal 66, 163-179.

Oweis, T., Hachum, A. and Pala, M. (2004b) Lentil production under supplemental irrigation in a Mediterranean environment. Agricultural Water Management Journal 68, 251-265.

Oweis, T., Hachum, A. and Pala, M. (2005) Faba bean productivity under rainfed and supplemental irrigation in Northern Syria. Agricultural Water Management Journal 73, 57-72.

Rego, T.J., Sahrawat, K.L., Wani, S.P. and Pardhasaradhi, G. (2007) Widespread deficiencies of sulfur, boron and zinc in Indian semi-arid tropical soils: on-farm crop responses. Journal of Plant Nutrition 30, 1569-1583.

Rockström, J., Barron, J. and Fox, P. (2003) Water productivity in rain-fed agriculture: challenges and opportunities for smallholder farmers in drought-prone tropical agroecosystems. In: Kijne, W.J., Barker, R. and Molden, D. (eds) Water Productivity in Agriculture: Limits and Opportunities for Improvement. CAB International, Wallingford, UK, pp. 145-162.

Rockström, J., Wani, S., Oweis, T. and Hatibu, N. (2007) Managing water in rainfed agriculture. In: Water for Food, Water for Life: a Comprehensive Assessment of Water Management in Agriculture. Sponsored by Ramsar, CGIAR, FAO and CBD. EarthScan, London, UK, pp. 315-348.

Sahrawat, K.L., Wani, S.P., Rego, T.J., Pardhasaradhi, G. and Murthy, K.V.S. (2007) Widespread deficiencies of sulphur, boron and zinc in dryland soils of the Indian semi-arid tropics. Current Science 93(10), 1-6.

Wani, S.P., Joshi, P.K., Ramakrishna, Y.S., Sreedevi, T.K., Piara Singh and Pathak, P. (2008) A new paradigm in watershed management: a must for development of rain-fed areas for inclusive growth. In: Swarup, A., Bhan, S. and Bali, J.S (eds) Conservation Farming: Enhancing Productivity and Profitability of Rain-fed Areas. Soil Conservation Society of India, New Delhi, India, pp. 163-178. 